\title{
MORFOLOGIA DE FRUTOS, SEMENTES E DE PLÂNTULAS DE JANAGUBA (Himatanthus drasticus (MART.) PLUMEL. -APOCYNACEAE) ${ }^{1}$
}

\author{
MANOELSILVAAMARO ${ }^{2}$, SEBASTIÃO MEDEIROS FILHO ${ }^{3}$, RENATO MENDES GUIMARÃES ${ }^{4}$, ELIZITAMARIATEÓFILO ${ }^{5}$
}

\begin{abstract}
RESUMO - O trabalho objetivou descrever e ilustrar aspectos morfológicos do fruto, semente e plântulas de janaguba (Himatanthus drasticus (Mart.) Plumel.). Nos ensaios realizados em laboratório e casa de vegetação do Departamento de Fitotecnia do Centro de Ciências Agrárias, da Universidade Federal do Ceará, em Fortaleza-CE, foram observados nos frutos os seguintes aspectos: tipo, deiscência, tamanho, coloração e consistência do epicarpo, mesocarpo, endocarpo e placenta. Na semente, verificou-se dimensão, coloração, textura e consistência do tegumento, forma e bordo, posição do hilo, micrópila e rafe, embrião, cotilédones, eixo hipocótilo-radícula e plúmula, enquanto na plântula observou-se protrusão da raiz primária e secundária, hipocótilo, epicótilo e plúmula. As observações foram realizadas com auxílio de lupa de mesa, microscópio estereoscópico e as medidas foram tomadas com paquímetro digital. $\mathrm{O}$ fruto é polispérmico, possui em média 42 sementes aladas e albuminosas, com germinação faneroepígea cotiledonar.
\end{abstract}

Termos para indexação: espécie arbórea, emergência, cotilédones, aspectos morfológicos.

\section{MORPHOLOGY OF JANAGUBA FRUIT, SEED AND SEEDLING (Himatanthus drasticus (MART.) PLUMEL.-APOCYNACEAE)}

\begin{abstract}
The objectives of this study were to describe and illustrate the morphological aspects of janaguba (Himatanthus drasticus (Mart.) Plumel.) fruit, seed and seedlings. All the experiments were conducted at the Laboratory of Seed Analysis of the Federal University of Ceará. The following characteristics were studied in janaguba fruits: type, dehiscence, dimension, consistency and coloration of the epicarp, mesocarp, endocarp and placenta. In janaguba seeds the characteristics studied were dimension, colour, texture, consistency of the tegument, shape, edges, hilum, micropyle and rafe positions, embryo, cotyledons, hypocotyl-radicle axes, and plumule. The janaguba seedling root system, hypocotyls, epicotyls, and first leaves were evaluated. Ruler and pachimeter were used to take the measurements, as well as optical microscope and magnifying glass. The janaguba fruit is full of seeds (42 seeds in average), winged; seeds are the albumin type and present epigeous germination.
\end{abstract}

Index terms: tree species, emergency, cotyledons, morphological aspects.

\section{INTRODUÇÃO}

A janaguba, pertencente à família Apocynaceae, é uma espécie arbórea que cresce até $7 \mathrm{~m}$ de altura, com folhagem densa nas extremidades dos ramos. Sua distribuição geográfica vai desde o sudeste do Brasil até a Guiana Francesa, Suriname e Guiana. No Brasil ocorre nos estados de Minas Gerais, Bahia,

\footnotetext{
${ }^{1}$ Submetido em 09/12/2004. Aceito para publicação em 06/06/2005. Parte da Dissertação de Mestrado, defendida pelo primeiro autor, em Agronomia/ Fitotecnia-UFC;

${ }^{2}$ Biólogo, mestre em Agronomia/Fitotecnia-UFC,. Fortaleza-CE;

${ }^{3}$ Engenheiro Agrônomo, D.Sc., Professor Ajunto do Depto. de Fitotecnia-
}

Sergipe, Alagoas, Pernambuco, Rio Grande do Norte, Ceará, Paraíba, Piauí, Maranhão, Pará e Roraima. É conhecida popularmente como tiborna, jasmim-manga e raivosa em Minas Gerais e Bahia, janaguba no Ceará, pau-de-leite no Piauí, joanaguba no Rio Grande do Norte, sucuúba na Amazônia (Plumel, 1991). No Ceará, essa espécie ocorre com maior freqüência na Chapada do Araripe, extremo sul do estado,

UFC. Fortaleza-CE, filho@ufc.br;

${ }^{4}$ Engenheiro Agrônomo, D.Sc., Professor Ajunto do Depto. de AgronomiaUFLA, Lavras-MG, renatomg@ufla.br;

${ }^{5}$ Engenheira Agrônoma, D.Sc., Pesquisadora do Depto. de Fitotecnia-UFC. Fortaleza-CE, elizita@ufc.br. 
onde é explorada por populares daquela localidade, cotidianamente e sem controle (Modesto, 1997).

A janaguba tem uma longa história de emprego na cura do câncer no Nordeste, porém, quase sem registro na literatura.

O conhecimento da morfologia das sementes é necessário para a identificação e certificação do material empregado nas análises de sementes (Oliveira e Pereira, 1984). Beltrati (1994) comenta que esses conhecimentos podem servir para melhorar a conservação da fauna e da flora, contribuir nos estudos de sucessão ecológica e regeneração dos ecossistemas florestais.

A identificação das espécies pode ser feita por meio da sistemática, da anatomia e da dendrologia. As características morfológicas das plantas também podem ser utilizadas na identificação. Os aspectos morfológicos da plântula foram enfatizados já há algum tempo, para identificar as plantas de determinada região, em estudo sobre ecologia da espécie, como para facilitar a interpretação de testes de germinação em laboratório pelos analistas de sementes (Oliveira, 1993).

Barroso et al. (1999) afirmam que tamanho, forma e tipo de deiscência dos frutos, são caracteres imprescindíveis para a classificação dos mesmos. Nesse sentido, os autores salientam que os estudos morfológicos de frutos contribuem para a identificação das espécies, bem como sua distribuição geográfica e interações com a fauna.

$\mathrm{Na}$ natureza, diversos fatores contribuem para a variabilidade da forma e tamanho de frutos e sementes. Vários autores ressaltam a importância dos caracteres estruturais externos e internos dos diásporos vegetais, uma vez que o tamanho dessas estruturas é indispensável para que se possa conhecer melhor determinada espécie (Raven et al., 1996).

Uma das maiores dificuldades encontradas pelos estudiosos de plantas silvestres é a carência de informações relacionadas à identificação das espécies, visto que a aquisição de material botânico para estudos, muitas vezes se torna difícil. Por outro lado, há preocupação da comunidade científica quanto aos estudos morfológicos e de propagação, no intuito de preservar a flora, principalmente, as espécies que se encontram em via de extinção.

O presente trabalho objetivou descrever e ilustrar os caracteres morfológicos do fruto, da semente e da plântula de janaguba.

\section{MATERIAL E MÉTODOS}

Coleta do material: os frutos e as sementes foram coletados, em várias plantas de janaguba selecionadas ao acaso, pertencentes à constituição florística da Floresta Nacional do Araripe (FLONA-ARARIPE), Área de Preservação Ambiental (APA), situada no altiplano da Chapada do Araripe, município de Crato, extremo sul do estado do Ceará. Os frutos e as sementes foram colhidos na parte aérea das plantas, em seguida armazenados em sacos plásticos e conduzidos ao Laboratório de Analise de Sementes do Departamento de Fitotecnia, do Centro Ciências Agrárias, Universidade Federal do Ceará, onde foram realizados os ensaios.

Para determinar o número de sementes por quilograma e o peso de mil sementes, utilizaram-se oito sub-amostras de 100 sementes, segundo recomendações de Brasil (1992).

Biometria e aspectos morfológicos do fruto: para a determinação biométrica do fruto, coletaram-se no final da maturação e antes do início da deiscência, frutos de dez matrizes de janaguba, distando no mínimo 100 metros entre si. Após a mistura e homogeneização dos frutos, 50 exemplares foram selecionados ao acaso, para medição individual do comprimento (do ápice à base), largura (lado direito ao esquerdo) e espessura (da parte dorsal à ventral), com auxílio de régua graduada em milímetros e paquímetro digital. $\mathrm{Na}$ mesma amostra, fez-se a abertura dos frutos com auxílio de canivete metálico para o registro do número e percentagem de sementes intactas e chochas por fruto. Consideraram-se intactas as sementes que apresentaram aparência normal quanto às estruturas externas e ao tamanho e chochas, as sementes que não apresentavam nenhum conteúdo além do tegumento. Nos estudos da morfologia do fruto observaramse os seguintes aspectos: tipo, deiscência, coloração e consistência do epicarpo, mesocarpo, endocarpo e placenta. As observações foram com auxilio de lupa de mesa com braço flexível.

Biometria e aspectos morfológicos da semente: no final da maturação (início da deiscência), 50 frutos foram amostrados, ao acaso, coletados de várias plantas de janaguba, conduzidos ao laboratório e secados à sombra por 15 dias, em condições ambientais (temperatura ambiente média $27,5^{\circ} \mathrm{C}$, mínima $23-26^{\circ} \mathrm{C}$, máxima $30-32^{\circ} \mathrm{C}$ e umidade relativa média de $68 \%$, conforme dados do Serviço de Meteorologia do Departamento de Engenharia Agrícola-UFC). Em seguida, realizou-se a extração manual das sementes, considerando-se apenas as intactas e sem sintomas de ataque de pragas. Posteriormente, 50 sementes foram selecionadas ao acaso para medição individual de comprimento (ápice à base), largura (lado direito ao esquerdo) e espessura (da parte dorsal à ventral), com e sem ala. Para os aspectos morfológicos das 
sementes, as observações realizaram-se com ajuda de microscópio estereoscópico binocular com aumento de 20 vezes. As observações foram realizadas com sementes não embebidas, considerando-se os seguintes aspectos: externos (tipo, dimensão, coloração, textura e consistência do tegumento, forma e bordos da semente, posição do hilo, da micrópila e da rafe) e internos (embrião, cotilédones, eixo hipocótilo-radícula e plúmula). As medidas foram tomadas com o auxílio de um paquímetro digital de marca Starrett 727, com resolução de $0,01 \mathrm{~mm}$.

Aspectos morfológicos da germinação e da plântula: para a avaliação da morfologia da germinação, duas subamostras de 50 sementes de mesmo lote foram selecionadas ao acaso e semeadas sobre papel toalha umedecido com água destilada na proporção de 2,5 vezes o peso do papel, em caixas plásticas tipo gerbox e colocadas em câmara de germinação à temperatura de $25^{\circ} \mathrm{C}$ com luz, avaliando-se a cada 24 horas, durante 15 dias. Foram consideradas germinadas as sementes com protrusão da raiz (maior de $25 \mathrm{~mm}$ ), observaram-se os seguintes aspectos: protrusão da raiz primária, hipocótilo, epicótilo e plúmula.

O crescimento da plântula ocorreu em casa de vegetação coberta com sombrite ( $50 \%$ de luz) e irrigação intermitente. Semearam-se 200 sementes, distribuídas em quatro repetições de 50 , em bandejas plásticas brancas $(25 \times 18 \times 10 \mathrm{~cm})$, entre substrato vermiculita. Foram consideradas plântulas as que apresentaram o início do desenvolvimento dos protófilos. As avaliações ocorreram aos 20 dias após a semeadura. Nesta fase, consideraram-se os seguintes caracteres: raízes (principal e secundárias), coleto, hipocótilo, cotilédones, epicótilo e protófilos de primeira ordem (Roderjan, 1983).

Para as determinações biométricas de frutos, sementes e peso de mil sementes foram calculados a média aritmética, desvio padrão, coeficiente de variação e intervalo de variação dos valores obtidos.

Os métodos e termos empregados para descrever os aspectos morfológicos de frutos, sementes, germinação e plântulas basearam-se nos trabalhos de Joly (1993), DamiãoFilho (1993), Beltrati (1994), Chaves (1994), Vidal e Vidal (1995), Amorim (1996) e Barroso et al. (1999).

\section{RESULTADOS E DISCUSSÃO}

Biometria do fruto e da semente: os valores médios referentes ao comprimento $(16,9 \mathrm{~cm})$, largura $(2,5 \mathrm{~cm}) \mathrm{e}$ espessura $(2,3 \mathrm{~cm})$ dos frutos de janaguba apresentam desuniformidade no tamanho, com base nos coeficientes de variação de 17,$8 ; 8,0$ e $13,0 \%$ respectivamente. O comprimento do fruto variou entre $12-30 \mathrm{~cm}$ (Tabela 1). Plumel (1991) cita que o fruto dessa espécie possui de $15-20 \mathrm{~cm}$ de comprimento por $2,5 \mathrm{~cm}$ de largura.

Observa-se, na Tabela 2, que as médias relativas à quantidade de sementes por fruto (42) e número de sementes intactas por fruto $(39,3)$ expressaram boa uniformização dos dados, o que é demonstrado pelos coeficientes de variação obtidos, 12,7 e 12,2\% respectivamente. Quanto às sementes chochas por fruto, verifica-se média baixa, considerando-se a quantidade de sementes por fruto. Considerando-se que as sementes foram pesadas com as alas, os 6\% de coeficiente de variação da determinação do peso médio de mil sementes $(43,2 \mathrm{~g})$ revelam que as sementes de janaguba não apresentam acentuada variação em relação ao peso.

Verifica-se (Tabela 3 ) que os valores médios do comprimento $(4,28 \mathrm{~cm})$ e largura $(3,4 \mathrm{~cm})$ das sementes com ala são significativamente maiores quando comparados com as medidas das mesmas sem ala $(1,66$ e $0,9 \mathrm{~cm}$, respectivamente). Tais estruturas, segundo Barroso et al. (1999), de modo geral, estão sempre relacionadas com a anemocoria, constituindo ótima estratégia de dispersão.

Aspectos morfológicos do fruto: o fruto de janaguba é do tipo folículo, cilíndrico, ligeiramente arqueado, em forma de chifre, polispérmico, possui média de 42 sementes (Tabela 2), seco, deiscente; com abertura por única fenda na sutura ventral ao longo da linha de união dos bordos do carpelo, caracterizando a deiscência septicida (Barroso et al., 1999). As dimensões variam entre $12-30 \mathrm{~cm}$ de comprimento, 1,8$3,0 \mathrm{~cm}$ de largura por 2,0-2,9cm de espessura (Tabela 1). Folículo quando imaturo apresenta epicarpo de coloração verde, quando maduro amarelo-esverdeada e após a deiscência marrom-escura; com 0,5-1,0mm de espessura; com rugas longitudinais (da base ao ápice) e saliências laterais. Mesocarpo coriáceo e de coloração marrom após a deiscência. Endocarpo liso, brilhoso, de consistência papirácea, de coloração bege

TABELA1. Média, desvio padrão, coeficiente de variação (CV)e intervalo de variação do comprimento, largura e espessura, obtidos em uma amostra de 50 frutos de janaguba

\begin{tabular}{lccrc}
\hline Determinações & $\begin{array}{c}\text { Média } \\
(\mathrm{cm})\end{array}$ & $\begin{array}{c}\text { Desvio } \\
\text { padrão }\end{array}$ & $\begin{array}{r}\text { CV } \\
(\%)\end{array}$ & $\begin{array}{c}\text { Intervalo de } \\
\text { variação }\end{array}$ \\
\hline Comprimento & 16,9 & 3,0 & 17,8 & $12-30$ \\
Largura & 2,5 & 0,2 & 8,0 & $1,8-3,0$ \\
Espessura & 2,3 & 0,3 & 13,0 & $2,0-2,9$ \\
\hline
\end{tabular}


TABELA 2. Peso de mil sementes e média, desvio padrão, coeficiente de variação e intervalo de variação do número e percentagem de sementes intactas e chochas por fruto, obtidos em uma amostra de 50 frutos de janaguba

\begin{tabular}{lcccc}
\hline Determinações & Média & Desvio padrão & C V $(\%)$ & Intervalo de variação \\
\hline $\mathrm{N}^{\circ}$ total de sementes & 42,0 & 5,31 & 12,7 & $33-51$ \\
$\mathrm{~N}^{\circ}$ sementes intactas & 39,3 & 4,81 & 12,2 & $30-41$ \\
$\mathrm{~N}^{\circ}$ sementes chochas & 2,7 & 1,61 & 59,4 & $0-5$ \\
$\%$ de sementes intactas & 93,7 & 3,67 & 3,9 & $87,5-100$ \\
\% de sementes chochas & 6,3 & 3,67 & 58,0 & $0-12,5$ \\
Peso de mil sementes $(\mathrm{g}) *$ & 43,2 & 0,25 & 6,0 & $3,93-4,70$ \\
\hline
\end{tabular}

*Sementes com $8,7 \%$ de umidade.

TABELA3. Média, desvio padrão, coeficiente de variação e intervalo de variação da espessura, comprimento e largura (com e sem ala), obtidos em uma amostra de 50 sementes de janaguba

\begin{tabular}{lcccc}
\hline Determinações & Média* & Desvio padrão & CV (\%) & Intervalo de variação \\
\hline Comprimento (com ala) & 4,28 & 0,58 & 13,6 & $3,30-5,50$ \\
Comprimento ( sem ala ) & 1,66 & 0,35 & 20,1 & $1,10-2,50$ \\
Largura (com ala) & 3,40 & 0,58 & 17,0 & $2,50-4,70$ \\
Largura (sem ala) & 0,90 & 0,15 & 0,2 & $0,60-1,20$ \\
Espessura (mm) & 1,16 & 0,14 & 12,3 & $0,76-1,50$
\end{tabular}

* Comprimento e largura $(\mathrm{cm})$.

clara e com ligeiras depressões deixadas pelas sementes (Figura 1). Placenta com aspecto esponjoso, ocupa grande parte do interior carpelar, apresenta depressões resultantes da sobreposição das sementes.

A descrição morfológica do fruto de janaguba está de acordo com as informações mencionadas por Barroso et al. (1999), sobre a morfologia dos frutos de algumas apocináceas. Contudo, os autores não fazem nenhuma menção sobre a morfologia de frutos do gênero Himatanthus. Em relação à deiscência dos folículos desta família, os autores afirmam que esse tipo de fruto possui epicarpo com estrutura muito simples e, à medida que o mesmo se aproxima da maturação, o epicarpo se torna seco. Aparentemente, o ressecamento diferencial das paredes parenquimáticas e exclerenquimáticas do pericarpo cria tensões, que determinam a abertura do folículo ao longo da linha de união bordular do carpelo.

Aspectos morfológicos da semente: a semente de janaguba é alada, com 3,3-5,0 cm de comprimento por 2,5$4,7 \mathrm{~cm}$ de largura com ala, $1,1-2,5 \mathrm{~cm}$ de comprimento por $0,6-1,2 \mathrm{~cm}$ de largura sem ala e $0,76-1,50 \mathrm{~mm}$ de espessura (Tabela 3). Núcleo seminífero elíptico. Testa áspera, rugosa, de coloração amarelo-madeira e sulcada; com expansão a ala concêntrica, membranácea, de coloração amarelo-madeira, transparente e quebradiça, facilmente destacável, com reentrâncias na margem e às vezes pontiaguda na base e no ápice. Tégmen de consistência coriácea com coloração castanha. Hilo sub-basal, sem forma definida, saliente, bem visível, apresenta tecido esponjoso no seu interior de coloração esbranquiçada, às vezes encontra-se voltado para o lado direito da semente. Rafe lenhosa, linear (4,72-12,60mm de comprimento por $0,95-1,86 \mathrm{~mm}$ de largura), ventral, saliente, longa, se estende do hilo ao ápice da semente, apresenta no seu interior um tipo de tecido esponjoso de coloração branca. Micrópila não perceptível. Endosperma delgado, plano, de coloração albo-amarelada, cobrindo os cotilédones e radícula. Embrião cotiledonar, axial, contínuo, de coloração brancoleitosa e de consistência carnosa. Cotilédones brancos, opostos, planos, delgados e flexíveis, foliáceos, sésseis, com nervuras peninérveas pouco conspícuas, margem inteira, ápice rombóide e base cordiforme. Eixo embrionário reto, cilíndrico, de coloração branca, mede aproximadamente um quinto do comprimento do embrião; eixo hipocótilo-radícula externo aos cotilédones, ponta da radícula lanceolada; plúmula não desenvolvida; gema apical rudimentar (Figuras 2, 3 e 4).

Aspectos morfológicos da germinação: a germinação é faneroepígea cotiledonar com emissão de raiz a partir do quinto dia da semeadura, rompendo o tegumento na base dorsal da semente, expondo também rapidamente o hipocótilo. Raiz de coloração branca, cilíndrica e com base pontiaguda. Com o desenvolvimento, a raiz adquire uma densa camada de pêlos simples, finos, branco translúcidos, que se entrelaçam e se adensam. Coifa fina, branco gelo, glabra e com base 

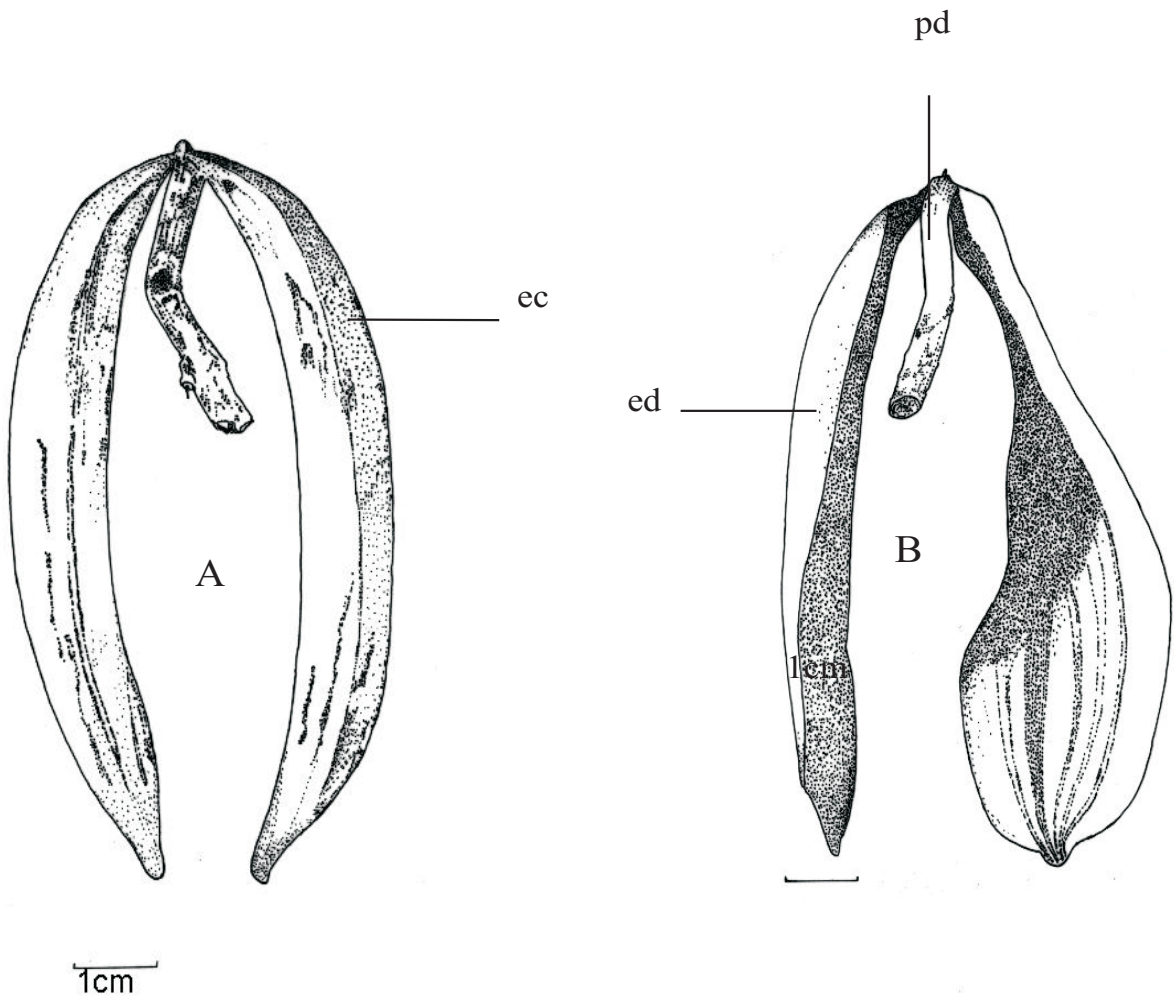

FIGURA 1. Aspectos morfológicos do fruto de janaguba: A-fruto maduro, antes da deiscência; B- fruto seco, pós-deiscente; ecepicarpo; ed-endocarpo; pd-pedúnculo.

B
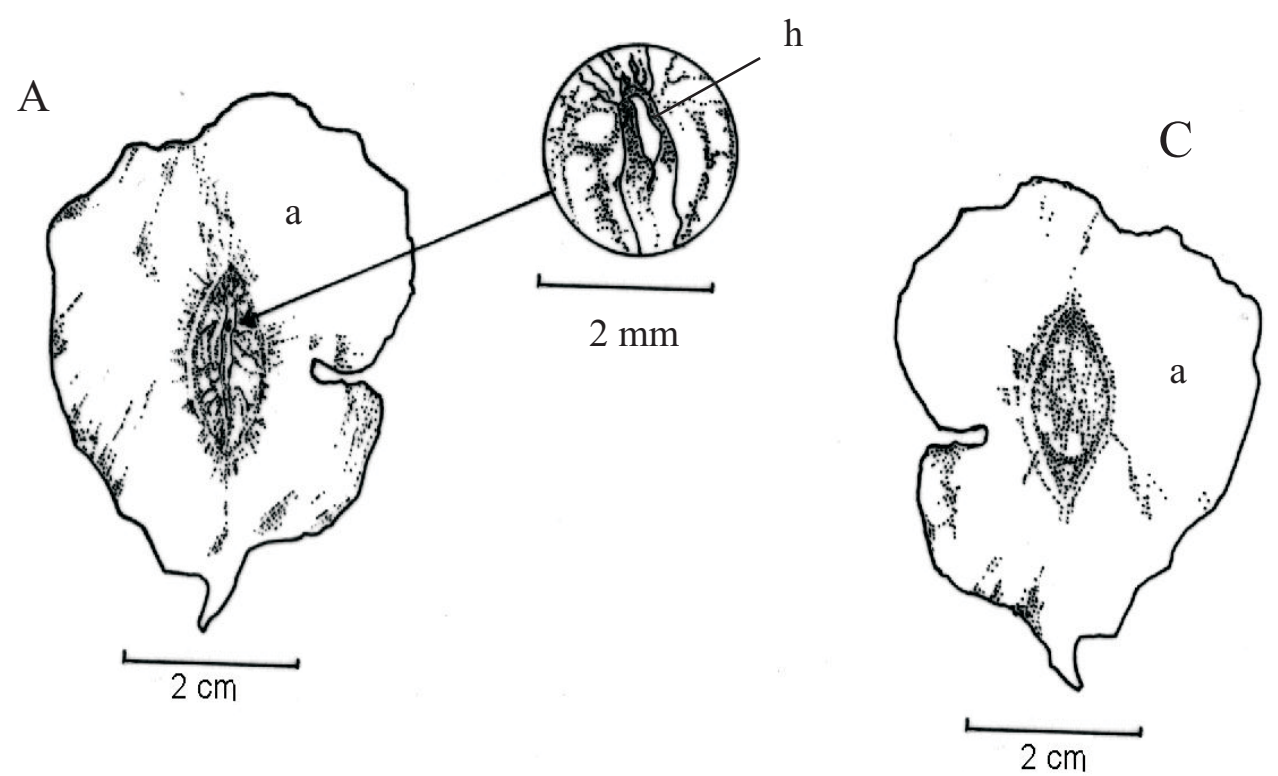

FIGURA 2. Aspectos externos da semente de janaguba: A-semente em vista ventral; B-detalhe do hilo; C-semente em vista dorsal; a-ala; h-hilo. 


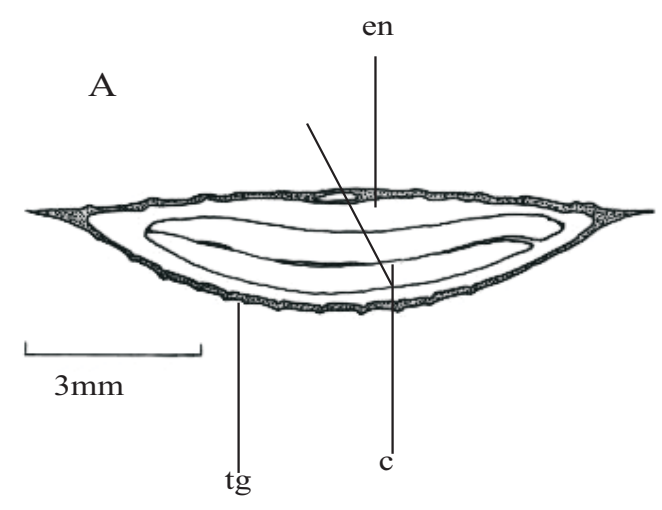

$\mathrm{B}$

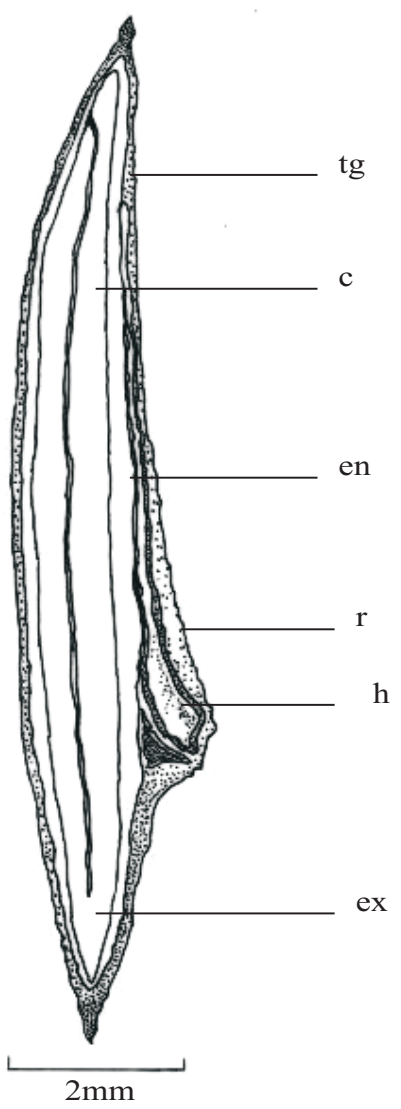

FIGURA3. Aspectos morfológicos externos e internos da semente de janaguba: A-semente em corte transversal; B-semente em corte longitudinal; c-cotilédones; en-endosperma; ex-eixo embrionário; $h$ - hilo; $r$-rafe; tg-tegumento.
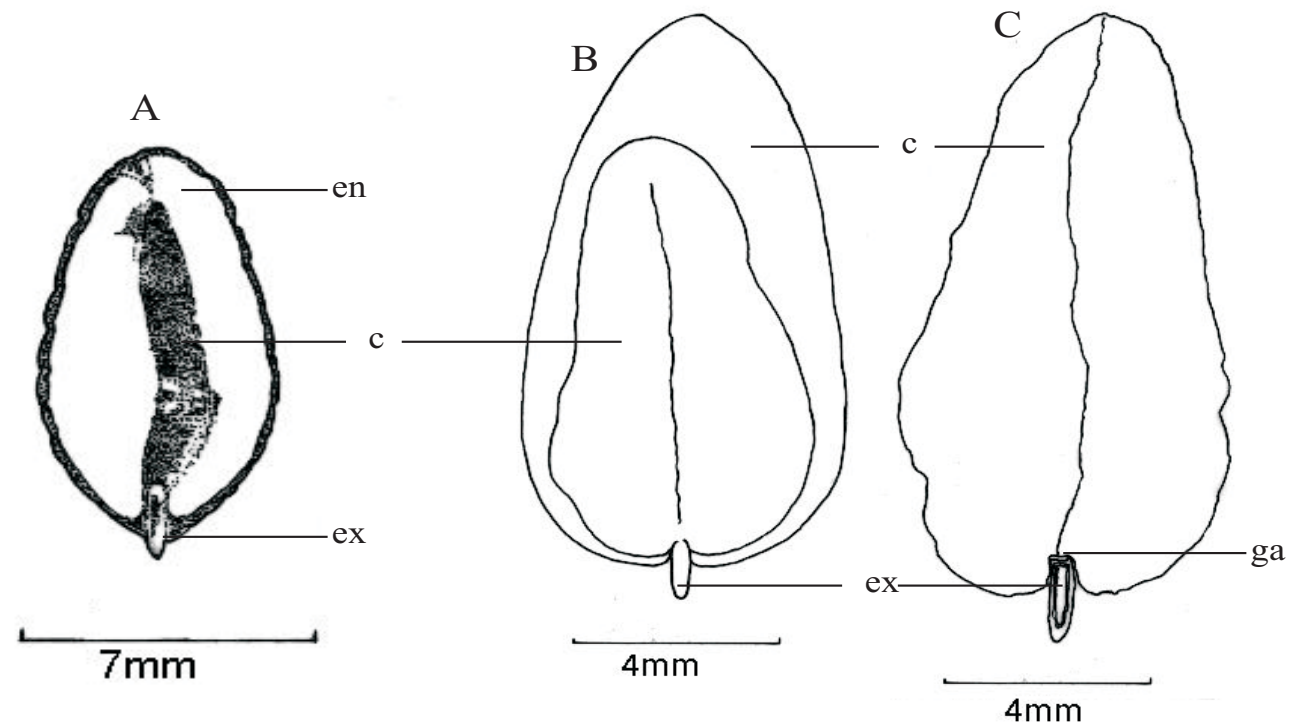

FIGURA 4. Aspectos da semente e do embrião de janaguba: A- semente sem tegumento; B-embrião; C-embrião sem um dos cotilédones; c-cotilédone; en-endosperma; ex-eixo embrionário; ga-gema apical. 
pontiaguda. Hipocótilo cilíndrico, glabro, verde intenso, longo curvado, formando um joelho no início da emergência da plântula, torna-se ereto e ergue os cotilédones; coleto caracterizado pelo maior diâmetro do hipocótilo e delimitado pela densa camada pelúcida. As primeiras raízes secundárias nascem imediatamente abaixo do coleto. Cotilédones opostos, sésseis, planos, foliáceos, isófilos produtores, com as mesmas características da fase de semente e permanecem aderidos ao tegumento até exaurir toda reserva endospermática. Com o desenvolvimento germinativo e na presença de luz tornamse fotossintetizantes, adquirindo coloração verde-escura, com nervação peninérvea em ambas faces; nervura principal de coloração verde clara, pouco evidente, imersa na face adaxial e impressa na face abaxial; margens inteiras, ápice obtuso e base cordiforme, na região de inserção dos cotilédones começa a se evidenciar a plúmula no início do seu desenvolvimento (Figura 5).

Morfologia da plântula: aos 20 dias da semeadura a plântula de janaguba apresenta sistema radicular axial; raiz

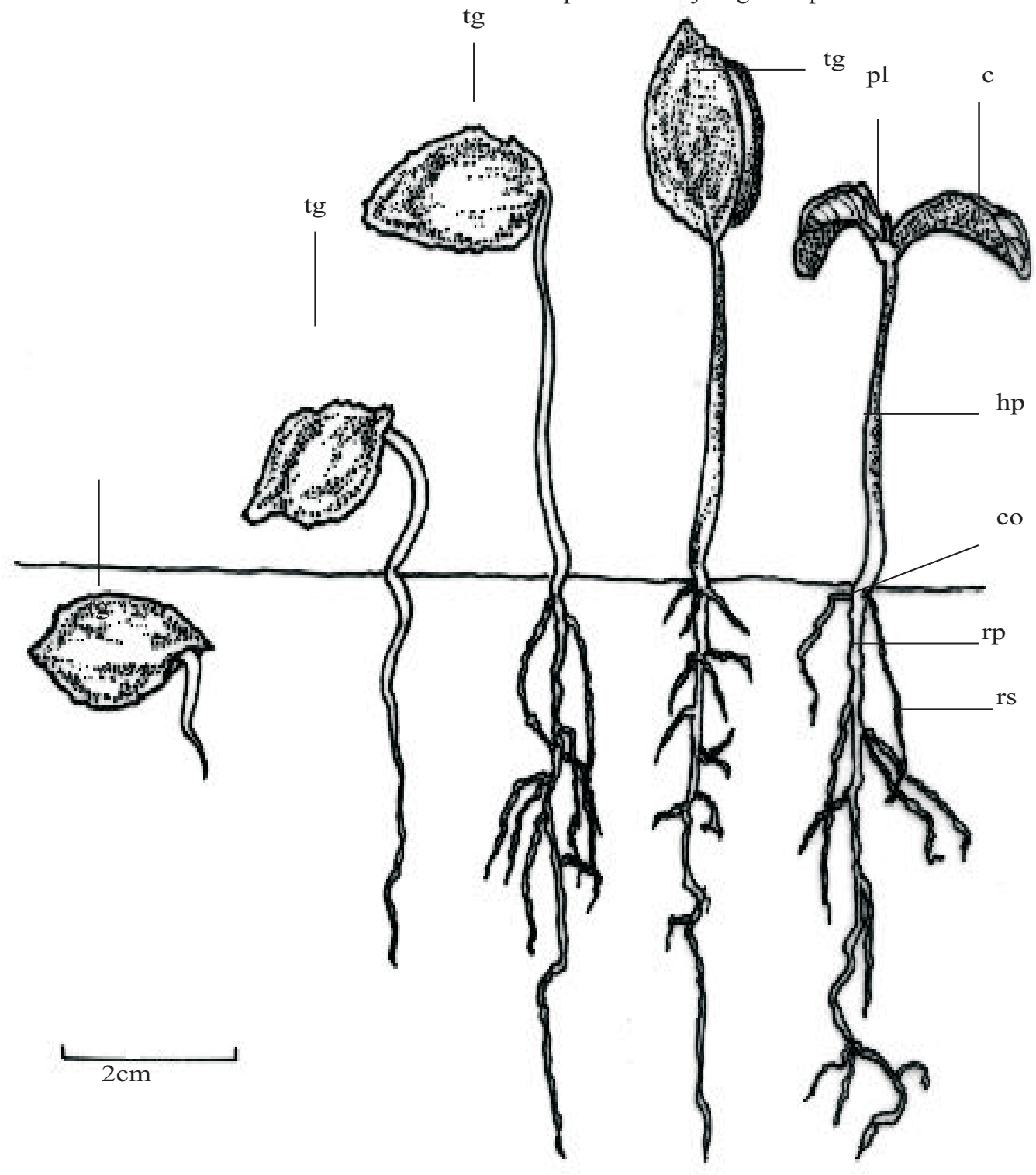

FIGURA 5. Aspectos da germinação epigeal de janaguba: c-cotilédone; co-colo; hp-hipocótilo; pl-plúmula; rp-raiz primária; rsraiz secundária; tg-tegumento. 
principal pivotante longa, cilíndrica, sinuosa, flexível e de coloração branco-amarelada; colo curto $(3 \mathrm{~mm})$ e evidenciado pelo maior diâmetro do hipocótilo. Ramificação secundária bem evidenciada com várias raízes finas e simples, flexíveis, curtas em relação à raiz principal. Hipocótilo de consistência herbácea, longo cilíndrico, verde, glabro e ereto. Os cotilédones, depois de libertados pelo tegumento e totalmente expandidos são foliáceos, isófilos opostos, do tipo produtor, curto peciolados (3mm), glabros, de coloração verde-escura, fotossintetizantes, com ápice obtuso e base cordiforme, nervação de coloração verde clara e pouco evidente, margem inteira, limbo com dimensões entre 10-12 mm de largura por $13 \mathrm{~mm}$ de comprimento; persistentes e não se desprendendo na fase de plântula. Epicótilo muito curto (1-3mm) na fase de plântula. Plúmula, situada na região de inserção dos cotilédones, tem início com a formação de dois protófilos alternos com aproximadamente $3 \mathrm{~mm}$ de um para outro, que no início do desenvolvimento apresentam tamanhos diferentes, são elípticos, curto peciolados (1-3mm), brilhosos, de coloração verde, com nervura principal robusta, nervuras secundárias numerosas e peninérveas nas duas faces, pouco inclinadas e margens inteiras (Figura 6).
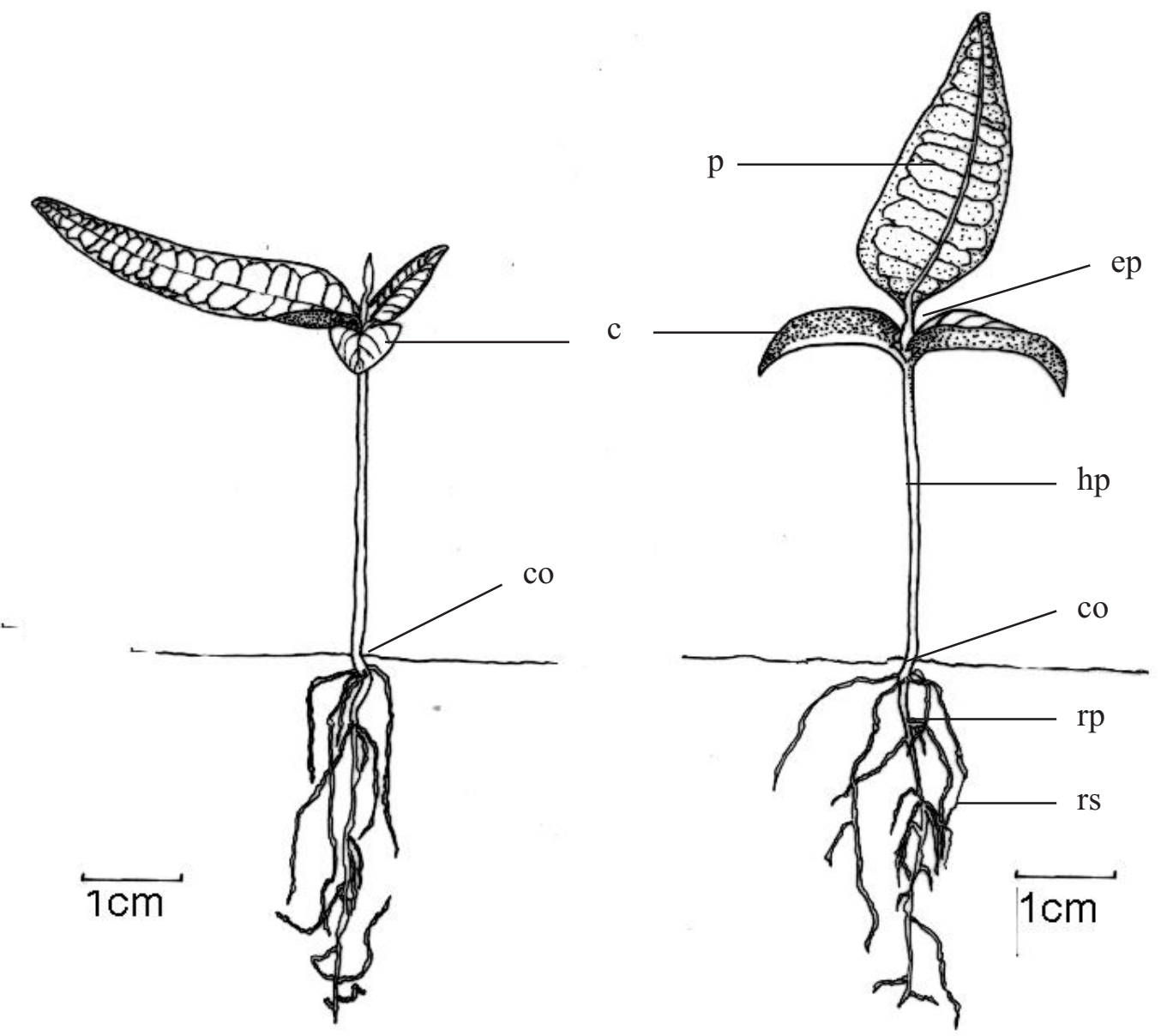

FIGURA 6. Aspectos da plântula de janaguba aos vinte dias da semeadura: c-cotilédone; co-colo; ep-epicótilo; hp-hipocótilo; pprotófilo; rp-raiz primária; rs-raiz secundária. 


\section{CONCLUSÃO}

O fruto de janaguba é polispérmico, possui em média 42 sementes albuminosas com germinação faneroepígea cotiledonar.

\section{REFERÊNCIAS}

AMORIM, I.L. Morfologia de frutos, sementes, germinação, plântula e mudas de espécies florestais de Lavras. 1996. $127 f$. Dissertação (Mestrado em Engenharia Florestal) - Universidade Federal de Lavras, Lavras, 1996.

BARROSO, G.M.; MORIN, M.P.; PEIXOTO, A.L.; ICHASO, C.L.F. Frutos e sementes: morfologia aplicada à sistemática de dicotiledôneas. Viçosa: UFV, 1999. 443p.

BELTRATI, C.M. Morfologia e anatomia de sementes In: CURSO DE PÓS-GRADUAÇÃO EM CIÊNCIAS BIOLÓGICAS, ÁREA DE BIOLOGIA VEGETAL. Apostila. Rio Claro: Departamento de Botânica / Instituto de Biociências / UNESP, 1994. 112p.

BRASIL. Ministério da Agricultura e Reforma Agrária. Regras para análise de sementes. Brasília: SNDA/DNDV/CLAV, 1992. $362 \mathrm{p}$.

CHAVES, M.M.F. Descrição morfológica de sementes, de plântulas e de mudas de $\mathbf{1 0}$ espécies arbóreas pioneiras na microrregião de Viçosa, Minas Gerais. 1994. 108f. Dissertação (Mestrado em Engenharia Florestal) - Universidade Federal Viçosa, Viçosa, 1994.
DAMIÃO-FILHO, C.F. Morfologia vegetal. Jaboticabal: FUNEP/ UNESP, 1993. 243p.

JOLY, A.B. Botânica: introdução à taxonomia vegetal. São Paulo: Nacional, 1993. 777p.

MODESTO, M.M.L.S. Aspectos ecológicos e sócio-econômicos de Himatanthus articulata (Wahl.) Woodson. "janaguba" da Chapada do Araripe. 1997. 55f. Monografia (Especialização em Botânica) - Universidade Regional do Cariri, Crato, 1997.

OLIVEIRA, E.C.; PEREIRA, T.S. Myrtaceae: morfologia da germinação de algumas espécies. In: CONGRESSO NACIONAL DE BOTÂNICA, 2., 1984. Porto Alegre. Anais... Porto Alegre: SBB, p.501-520.

OLIVEIRA, E.C. Sementes florestais tropicais In: AGUIAR, I.B.; PIÑA-RODRIGUES, F.C.M.; FIGLIOLIA, M.B. Sementes florestais tropicais. Brasília: ABRATES, 1993. p.175-213.

PLUMEL, M.M. Le genre Himatanthus (Apocinaceae). Revisión taxonomique: bradea. Boletim do Herbarium Bradeanu, Rio de Janeiro, v.5, p.1-20, 1991.

RAVEN, P.H; EVERT, R.F.; EICHHORN, S.E. Biologia vegetal. 6.ed. Rio de Janeiro: Guanabara Koogan S/A, 2001. 928p.

RODERJAN, C.V. Morfologia do estádio juvenil de 24 espécies arbóreas de uma floresta com araucária. 1983. 148f. Dissertação (Mestrado em Engenharia Florestal) - Universidade Federal do Paraná, Curitiba, 1983

VIDAL, W.N.; VIDAL, M.R. Botânica-organografia. 3.ed. Viçosa: UFV, 1995. 114p.

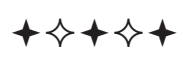

